\title{
EFFECTIVENESS OF 2 D ANIMATED FILM ON NUTRITION AND EALTH PRACTICES OF RURAL WOMEN
}

\author{
NIDA FATIMA HAZARI ${ }^{1} \&$ V. VIJAYA LAKSHMI ${ }^{2}$ \\ ${ }^{I}$ Research Scholar, Department of Foods \& Nutrition College of Home Science, PJTSAU, Hyderabad, India \\ ${ }^{2}$ Professor \& Head, Department of Foods \& Nutrition College of Home Science, PJTSAU, Hyderabad, India
}

\begin{abstract}
Education of rural women assumes great importance to enable them to get the fullest benefit of globalization and it is the women who nurture the child and takes care of the overall development particularly in formative years. A quasi-experimental pretest and post-test research design was used to assess the effectiveness of the developed e-learning education material on the nutrition, health and hygiene practices of rural women (100 experimental group; 30 control group) in 3 villages of Rangareddy district, Telangana. A standardized questionnaire developed for the study was used to collect information regarding the nutritional practices of the respondents. E-learning education material developed for the study using animation included educational content on nutritional needs of children (0-6years), pregnant and lactating women, the most common nutritional deficiencies and strategies to control and prevent them. The $2 \mathrm{D}$ animated film developed was shown to the experimental group for a period of 6 months. The posttest findings revealed that the experimental group showed higher scores in the post intervention (30.7) than pre intervention scores (24.5) which indicated that there was a positive effect of e-learning education material on rural women not only in terms of improvement in gain in scores but also in the adoption of desirable practices.

KEYWORDS: E-Learning, Rural Women, 2d Animated Film \& Nutritional Practice
\end{abstract}

Received: Sep 02, 2017; Accepted: Sep 22, 2017; Published: Oct 06, 2017; Paper Id.: IJCMSOCT20176

\section{INTRODUCTION}

Rural women are key actors in solving the major issues on the development agenda for the coming century, including the need to manage the environment in a sustainable manner, control the exploding rate of population and urbanization, food security, human needs with regard to health, education and literacy and in the elimination of poverty.

Rural women are also a major force in environmental protection because they live and work in close contact with the ecosystem, possess an intimate knowledge of local biodiversity and can help safeguard natural resources for the future by practicing sustainable agriculture, forestry and fisheries.

For the development of the rural environment, education should be taken up on a priority basis since it is the basis for creativity and foresightedness that triggers change; it helps in economic growth, quality of life and the quality of human resource.

Education takes us away from tradition backwardness, darkness, poverty, misery and overpopulation and directs us towards enlightenment, prosperity and happiness. Education does not merely mean the acquisition of knowledge or experience, but it means the development of habits, attitudes and skills which help a person to lead a 
full and worthwhile life.

Education of rural women also assumes great importance to enable them to get the fullest benefit of globalization and it is also of paramount importance for the development of individuality as an instrument for strengthening socially useful skills, habits and attitudes of common citizenship. It is the women who nurture the child and take care of his/her overall development particularly in formative years. Hence, she has to be educated to provide a sound knowledge base for upbringing of the child.

As described by Inan and Lowther (2007), when computer - supported learning is coupled with the limitless connectivity of the Internet, educational opportunities expand beyond the barriers of traditional learning environments.

Multimedia helps in creating messages that enhance learning, giving direct information without bias, promoting medical decision support and expert advice with tailoring the information to age, sex, language, literacy level, ethnic background, socio - economic status, medical history and helps consumers ask better questions and get involved in their nutrition treatment plans.

Thus multimedia can be defined as the seamless integration of text, graphics, animation, audio, still images and motion video in a way that provides individual users with high levels of control and interaction. Therefore, the evolution of multimedia is a story of the emergence and convergence of these technologies.

\section{General Objective}

The main objective of the study was to develop an e - nutrition education material and assess its effectiveness on the nutritional practices of rural women.

\section{Nutrition and Health Practice}

Women play an important role within the household and are responsible for water supply, environmental and personal hygiene, food distribution and preventive health activities. Child health and survival enhanced by better hygiene, improved nutrition and feeding practices and timely medical intervention. These practices of the mother might be influenced by innumerable factors influenced mainly by local tradition and culture.

A study of knowledge and adoption of selected health and nutritional practices of rural women in Belgaum district, Karnataka (Vani, 2007) found that, 31.33 percent of the respondents had high, 49.34 percent had medium and the remaining 19.33 percent had low levels of knowledge, regarding health and nutritional practices.

\section{MATERIALS AND METHODS}

In the present study quasi experimental design has been used for pre - post testing with a control group to assess the effectiveness of the developed material on the practices of the rural masses before and after the educational intervention.

Research design:

Design of the experiment: Assessment practice before and after intervention

Number of villages: 3

Number of treatments: 1 


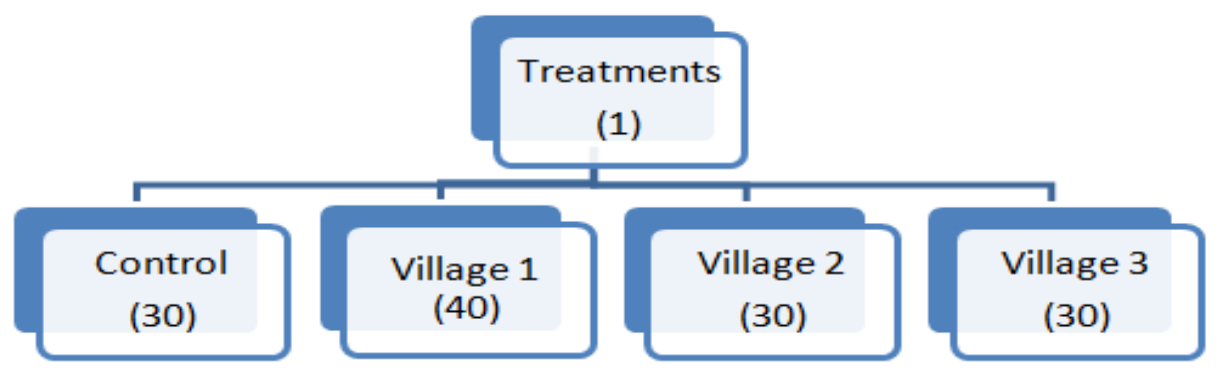

Figure 1: Categorization of Respondents in Three Different Villages in the Experimental Group and Control Group

A total sample of 130 rural women belonging to the reproductive age group of (15-49) years as shown in figure were selected from three villages namely Pudur, Gangupaly and Mirzapur of Pudurmandal, Rangareddy district, Telangana. The control group constituted of 30 women, 10 from each village and the rest of 100 rural women were divided among the three villages which comprised the experimental group.

Table 1: Distribution of Respondents According to their Profile Characteristics in Experimental Group and Control Group

\begin{tabular}{|c|c|c|c|c|c|c|}
\hline \multirow[t]{2}{*}{ S. No } & \multirow[t]{2}{*}{ Variable } & \multirow[t]{2}{*}{ Category } & \multicolumn{2}{|c|}{$\begin{array}{c}\text { Experimental Group } \\
\qquad \mathbf{N}=\mathbf{1 0 0} \\
\end{array}$} & \multicolumn{2}{|c|}{$\begin{array}{c}\text { Control Group } \\
\mathbf{N}=\mathbf{3 0}\end{array}$} \\
\hline & & & $\mathrm{F}$ & $\%$ & $\mathrm{~F}$ & $\%$ \\
\hline \multirow[t]{3}{*}{1} & Young women & $15-25$ years & 40 & 40 & 9 & 30 \\
\hline & Middle aged women & $26-35$ years & 44 & 44 & 14 & 47 \\
\hline & Old women & $36-49$ years & 16 & 16 & 7 & 23 \\
\hline \multirow[t]{2}{*}{2} & Marital status & Married & 82 & 82 & 26 & 87 \\
\hline & & Unmarried & 18 & 18 & 4 & 13 \\
\hline \multirow[t]{5}{*}{3} & Education & Illiterate & 15 & 15 & 0 & 0 \\
\hline & & primary school & 14 & 14 & 26 & 86 \\
\hline & & middle school & 8 & 8 & 2 & 7 \\
\hline & & high school & 48 & 48 & 0 & 0 \\
\hline & & College & 15 & 15 & 2 & 7 \\
\hline \multirow[t]{3}{*}{4} & Occupation & house wife & 81 & 81 & 23 & 76 \\
\hline & & working women & 8 & 8 & 5 & 17 \\
\hline & & Student & 11 & 11 & 2 & 7 \\
\hline \multirow[t]{2}{*}{5} & Family type & Nuclear & 55 & 55 & 18 & 60 \\
\hline & & Joint & 45 & 45 & 12 & 40 \\
\hline \multirow[t]{4}{*}{6} & Income -poor & upto 2000 & 2 & 2 & 2 & 7 \\
\hline & -low & $2000-5000$ & 39 & 39 & 5 & 17 \\
\hline & -medium & $5000-10000$ & 40 & 40 & 23 & 76 \\
\hline & -high & $>10000$ & 19 & 19 & 0 & 0 \\
\hline \multirow[t]{3}{*}{7} & Possession of Audio-visual material & Television & 51 & 51 & 18 & 60 \\
\hline & & Mobile & 36 & 36 & 12 & 40 \\
\hline & & CD Player/Laptop & 13 & 13 & 0 & 0 \\
\hline \multirow[t]{3}{*}{8} & Mass media exposure & Never & 2 & 2 & 2 & 7 \\
\hline & & occasional & 2 & 2 & 28 & 93 \\
\hline & & daily & 96 & 96 & 0 & 0 \\
\hline \multirow[t]{2}{*}{9.} & Urban contact & Medium & 77 & 77 & 30 & 100 \\
\hline & & High & 23 & 23 & 0 & 0 \\
\hline
\end{tabular}

The data were collected at the beginning of the study in both the experimental group and the control group. A standardized knowledge questionnaire on aspects of nutrition, health and hygiene was developed for the present research. After the collection of the relevant data, an E - nutrition education material, "educating women through e - 
learning', a digital nutrition education package called 'EWE', a short educational film of 15 minutes duration was prepared for the rural women with a well-defined concept and properly formulated dialogues which included basic information on nutrition, health and hygiene. The major focus in developing e - nutrition education material was to cover aspects like nutritional needs of children (0- 6 years), pregnant and lactating women, maintaining proper hygiene and sanitation, diarrhea, immunization, malaria and de-worming, as the most common nutritional deficiencies seen in these vulnerable groups of rural population and strategies to prevent and control these deficiencies.

The educational intervention was shown to the experimental group only for a period of 6 months. After the intervention, final data were collected in both the groups. The practice questionnaire which composed of --- questions was given to both the experimental and control groups after a period of six months to assess the effectiveness of the animated film on the practices of rural women.

\section{RESULTS}

The present study showed that the e - learning education intervention, conducted over a period of 6 months had a positive impact on attitude on nutrition and health among rural women.

Table 2: Distribution of KAP Scores in Experimental Group and Control Group before Educational Intervention

\begin{tabular}{|c|c|c|c|c|}
\hline & $\begin{array}{c}\text { Experimental Group } \\
(\mathbf{N = 1 0 0 )}\end{array}$ & \multicolumn{2}{c|}{$\begin{array}{c}\text { Control Group } \\
(\mathbf{N = 3 0 )}\end{array}$} \\
\hline Scores & \multicolumn{2}{|c|}{ Pre - Test N \% } & \multicolumn{2}{|c|}{ Pre - Test N \% } \\
\hline Practices & & & & \\
\hline $15-20$ & 11 & 11 & 0 & 0.00 \\
\hline $20-25$ & 33 & 33 & 8 & 26.67 \\
\hline $25-30$ & 53 & 53 & 22 & 73.33 \\
\hline$>=30$ & 3 & 3 & 0 & 0.00 \\
\hline
\end{tabular}

Table 3: Distribution of KAP Scores in Experimental Group and Control Group after Educational Intervention

\begin{tabular}{|c|c|c|c|c|}
\hline & \multicolumn{2}{|c|}{$\begin{array}{c}\text { Experimental } \\
\text { Group (N=100) }\end{array}$} & \multicolumn{2}{c|}{$\begin{array}{c}\text { Control Group } \\
(\mathbf{N = 3 0})\end{array}$} \\
\hline Scores & \multicolumn{2}{|c|}{ Post - Test N \% } & \multicolumn{2}{c|}{ Post - Test N \% } \\
\hline Practices & & & & \\
\hline $15-20$ & 0 & 0 & 0 & 0.00 \\
\hline $20-25$ & 0 & 0 & 8 & 26.67 \\
\hline $25-30$ & 21 & 21 & 22 & 73.33 \\
\hline$>=30$ & 79 & 79 & 0 & 0.00 \\
\hline
\end{tabular}

Table 4: Gain in Practice Scores of Respondents after Exposure to the 2D Animated Film among Rural Women

\begin{tabular}{|c|l|c|c|c|c|c|}
\hline \multirow{2}{*}{ S. No } & \multirow{2}{*}{ Category } & \multicolumn{2}{|c|}{ Mean Practice Score } & \multirow{2}{*}{$\begin{array}{c}\text { 'T' Value } \\
\text { Before }\end{array}$} & $\begin{array}{c}\text { Gain in } \\
\text { Practice }\end{array}$ & $\begin{array}{c}\text { Quantum of } \\
\text { Improvement }\end{array}$ \\
\hline 1 & Experimental group & $24.59 \pm 0.36$ & $30.70 \pm 0.16$ & $15.42 * *$ & 6.11 & 1.25 \\
\hline 2 & Control group & $24.59 \pm 0.36$ & $24.59 \pm 0.36$ & - & - & - \\
\hline
\end{tabular}

** - Significant at $1 \%$ 


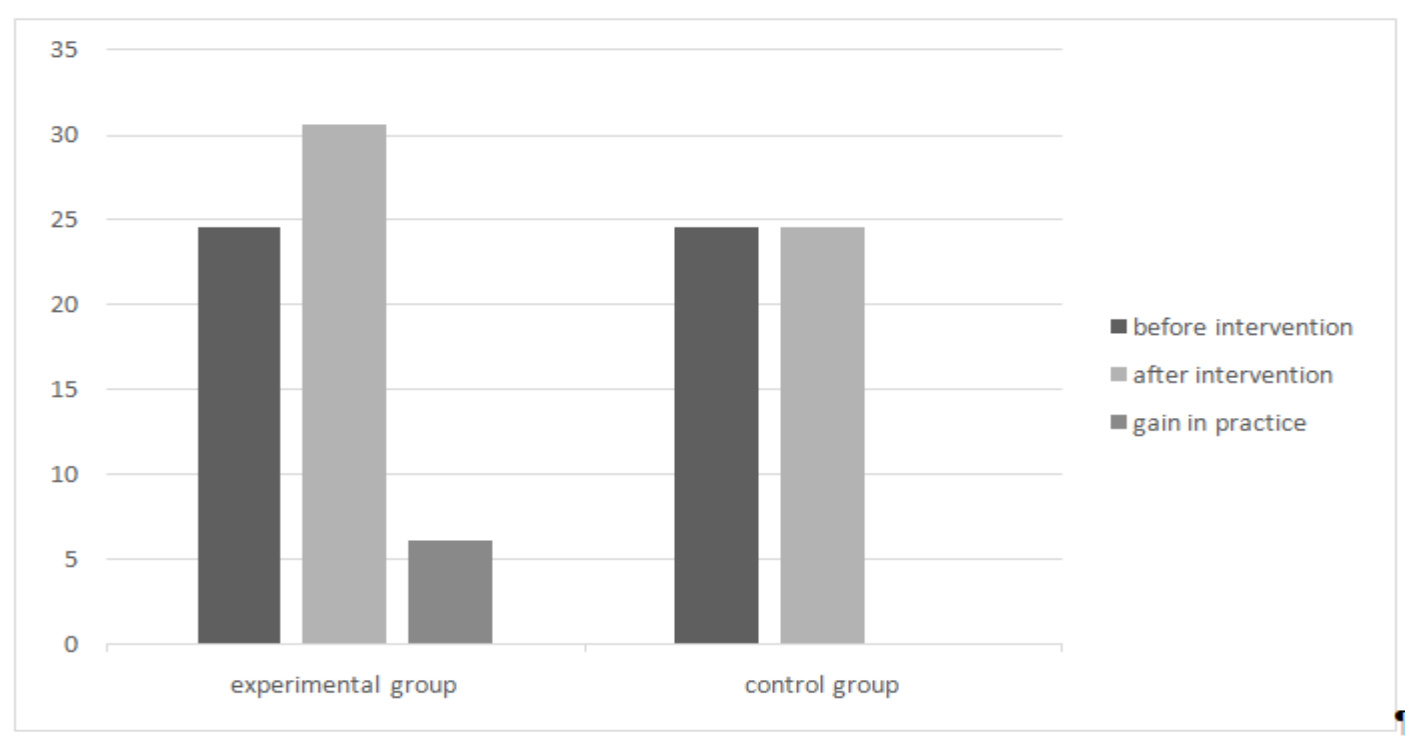

Figure 2: Mean Attitude Scores and Gain in Practice of Respondents in Experimental and Control Group Before and After Exposure to the 2 D Animated Films

\section{DISCUSSIONS}

According to table 2, scores for practice was found that, 53 percent subjects who scored between $25-30$, followed by 33 percent subjects who scored between $20-25$ and 11 percent subjects scored between $15-20$, and only 3 percent who scored $>=30$, before the intervention. Whereas, in the control group, the corresponding values showed that, 26.67 percent subjects scored between $20-25$ and 73.33 percent subjects scored $25-30$, before the intervention.

In the present study, the overall percentage score of correct answers for practice was 70.25 percent and after the educational intervention, the percentage of correct answers by the sample for practice was 87.71 per cent. Thus, it can be concluded that there was a good amount of increase in practices through the e - learning intervention program with regard to nutrition, health and hygiene.

The practice scores at post intervention, according to table 3, majority of the respondents had moved to upper category of scores $>=30$ as 79 per cent and 21 per cent of the subjects scored between $25-30$ whereas in the control group the values were the same and showed no change.

Results presented in Table 5, indicate that before exposure to the animated film, mean practice scores for the experimental group and the control group was 24.59. The mean practice scores after exposure was 30.70 in the experimental group and for the control group it was 24.59. The gain in practice score was 6.11 for the experimental group.

Rajbir et al. (2008) showed that, the urban elderly had higher scores than the rural elderly, in a study to evaluate the impact of nutrition counseling, as they were more literate and exposed to media like newspaper, radio and television

The present study showed that, the e - learning education intervention, conducted over a period of 6 months had a positive impact on nutrition practices of rural women.

The implementation period of the intervention, its concept, content and presentation strategies were the major factors, that have contributed to the outcome of the intervention.

Results presented in Table 4 indicate that, before exposure to the animated film, mean practice scores for the 
experimental group and the control group was 24.59. The mean practice scores after exposure was 30.70 in the experimental group and for the control group it was 24.59. The gain in practice score was 6.11 for the experimental group.

There was a positive correlation between mother's education and hygienic practices (Akorede and Abiola, 2013).

Increasing the level of education also implies adoption of modern ideas, while gradually leading to the dereliction of traditional practices regarding child care. A study conducted in Nigeria showed that, mothers' educational level and occupation influenced both time and duration of breast feeding and introduction of milk formula (Igbedioh, 1996).

Awareness score was significantly associated with age, education and income while the attitude score was significantly associated with age and education. Practice score was significantly associated with age, education and occupation. Awareness, attitude and practice score of women having a history of cancer in a family or relative was significantly higher than women without history (Tripathi et al. 2014).

Dhimal et al. (2014) found a significant association between prevention practices and the educational levels of the participants in a community based knowledge, attitude and practices study of dengue fever in Nepal.

Adoption of improved dairy farming practices is very essential for successful dairy farming. A study conducted in the hills and valley regions of Manipur, by Shyam et al. (2014) depicted that, in the hill area region there was a significant relationship between adoption of practices, with selected variables like age, education, income, type of house, communication source, personal cosmopolitan and mass media exposure. It was also seen that education and urban contact showed significant but negative correlation.

The maternal employment and the educational characteristics became a constraint for the good child - care practices as the alternative caregivers took over a more important role in the child care as the mothers join the work force (Kulwaet al. 2006). Educational level was associated with good practices.

Sillah et al. (2013) concluded that, higher maternal age and socio - economic status are correlated with higher practice and KAP scores. Age, education and income were significantly correlated with practice score, among rural women (Aruna et al. 2013).

Participants, who had completed higher secondary and secondary education, were found to have a better practice compared to the illiterate group (Dhimal et al. 2014).

\section{CONCLUSIONS}

Rural development aims at providing rural people's livelihood in a sustainable manner, both socially and environmentally through better access to assets (natural, physical, human, technological and social capital) and services and control over productive capital (in its financial or economic and political forms) that enable them to improve their livelihood in a sustainable and equitable basis.

Nutrition education is used by many countries to improve the nutritional well being with the general objective to make best use of existing food resources and to become familiar with food based dietary guidelines for good health and nutrition and bring about meaningful changes in dietary practices that results in improved health and nutritional status.

The IT's and multitude technology has made many possibilities for e- learning environment and this certainly has direct implications to indigenous content development initiatives in the country. 
The $2 \mathrm{D}$ animated film developed to assess the effectiveness of the nutritional practices of rural women showed a positive result with marked changes in better understanding of practices in the experimental group where as there was no change in the control group.

It is the demand of the day that new educational technologies should be adopted in order to provide a modern education with new teaching methodologies in order to reduce the digital divide and to support the process of rural development.

\section{REFERENCES}

1. Akoerede, Quadri and Abiola, Ojure. 2013. Assessment of nutritional status of under - five children in Akure South local government, Ondo state, Nigeria. IJRRAS 14 (3). Vol 14. Issue 3.

2. Aruna, R. T., Sarojani, J. K., PushpaBharati. 2013. Impact of education intervention on knowledge regarding iodine deficiency disorder. Karnataka Journal. Agric. Sci, 26 (1) : $124-127$.

3. Dhimal, M., Aryal, K.K., Dhimal, M.L. 2014. Knowledge, Attitude and Practice regarding Dengue fever among the healthy population of Highland and Lowland communities in Central Nepal. Plos. ONE 9 (7).

4. Iqbedioh, S.O., Oqbeni, A.O., Adole,G.M.1996. Infant weaning practices of some Tiv women resident in Mkurdi, Nigeria. Nutr Health $11(1): 13-28$.

5. Kulwa,K. B., Kinabo, J. L., Modest, B. 2006. Constraints on good child care practices and nutritional status in urban Dar-es - Salaam, Tanzania. Food Nutr Bull. Sep; 27 (3) : 236 - 44.

6. Sillah, F., Ho, H. J and Chao, J. C. 2013. The use of oral rehydration salt in managing children under 5 year old with diarrhea in the Gambia: knowledge, attitude, and practice. Nutrition.Nov - Dec; 29(11 - 12) : 1368 - 73.

7. Shyam,Singh., Singh, K., Chakravarty, $R$ and Imtiwati, P. 2014.Differential Adoption of Improved Dairy Husbandry Practices in Hill and Valley Regions of Manipur (India).IJAS. 2014; 4(3): 509-514.

8. Tripathi, N., Kadam, Y.R., Dhobale, R.V. 2014. Barriers for early detection of cancer amongst Indian rural women. South Asian J Cancer. Apr; 3 (2) : 122 - 7.

9. Vani. P. 2007. A Study on knowledge and adoption of selected health and nutritional practices by rural women in Belgium district, Karnataka. M.Sc. (Agri) (Degree)Department of Agricultural Extension Education (Department)

10. Rajbir, Sachdeva, Seema Grewal, Anita Kochhar and Paramjit Chawla. 2008. Efficacy of Nutrition Counselling on Knowledge, Attitudes and Practices of Urban and Rural Elderly Males. Stud. Home Comm. Sci., 2(1): 65-68.

11. Inan, Fethi and Deborah, Lowther. 2007. A Comparative analysis of Computer - Supported Learning Models and Guidelines. Francisco Milton Mendes Neto and Francisco Brasileiro. Advances in Computer - Supported Learning. Information Science Publishing. PA, USA. $p-2$. 
